\title{
Filosofie met het eigen bestaan als inzet: \\ Inhoud en actualiteit van Foucaults late werk
}

Steven Dorrestijn

[Een iets verkorte versie gepubliceerd in: Wijsgerig Perspectief 49/2 (juni 2009)]

\section{Inleiding}

In zijn werk uit de jaren voor zijn dood in 1984 lijkt het wel of Foucault 180 graden van richting verandert. De nadruk op de 'macht' verruilt hij voor een onderzoek naar de 'zorg voor zichzelf'. Dit artikel geeft een inleiding en overzicht van dit late werk van Foucault. Bovendien wordt de actuele betekenis ervan geïllustreerd door het in te zetten voor een analyse van maatschappelijke problemen rond nieuwe technologieën. Juist de wending in Foucaults late werk maakt dat zijn benadering blijvende waarde krijgt voor de analyse van actuele problemen, omdat hij meer dan ooit tevoren op positieve wijze zijn eigen gedachten uitwerkt. De ontmanteling van 'het subject' uit zijn eerdere werk wordt nu aangevuld met aanknopingspunten om te onderzoeken hoe in onze eigen tijd nieuwe vormen van subjectiviteit worden voortgebracht.

Filosofie met het eigen bestaan als inzet

Foucault was zich sterk bewust van de drastische koerswijzigingen die hij telkens maakte. Er zou een geschiedenis te schrijven zijn van zelfreflecties waarin hij telkens opnieuw poogt zijn eigen werk te overzien en er eenheid in aan te brengen. Opmerkelijk is bijvoorbeeld de ontwikkeling in de manier waarop Foucault zichzelf als auteur presenteerde. Lange tijd cultiveerde hij een sfeer van geheimzinnigheid rond zijn eigen persoon. In een interview bij het befaamd geworden debat dat hij op de Nederlandse televisie voerde met Noam Chomsky, verklaarde Foucault bijvoorbeeld tegenover Fons Elders: 'Mijn persoonlijk leven bestaat niet' (Elders 1972, 2). Een andere interviewer kreeg het nog bonter: 'Mijn beste vriend, filosofen worden niet geboren ... zij bestaan, en dat volstaat' (DE, II, 678). In totaal contrast daarmee zegt Foucault in een later interview: '... ik zou kunnen zeggen dat ik er in zekere zin altijd aan heb gehecht dat mijn boeken fragmenten van een autobiografie zouden zijn. Mijn boeken waren altijd mijn persoonlijke problemen met waanzin, met gevangenissen, met seksualiteit' (DE, II, 1566).

Met de bundeling van de interviews in de Dits et Écrits en inmiddels een stapeltje biografische boeken is het mogelijk om met de wijsheid van achteraf terug te kijken. Dan blijkt hoe sterk bij Foucault altijd het verband tussen zijn leven en werk was, ook toen hij 
zichzelf met alle macht buiten beeld probeerde te houden. Een korte terugblik via de hoofdperioden in Foucaults werk kan dit verduidelijken.

In de archeologische periode brengt Foucault in zijn boeken de 'dood van de mens' naar voren. Het begrip van het subject wordt gedecentreerd. Hij wil daarmee de idee afwijzen dat geneeskunde, psychologie en filosofie steeds beter weten te doorgronden wat de mens ten diepste is. Deze ideeën weerspiegelen zich in Foucaults eigen leven in de poging om voor anderen ongrijpbaar te blijven, veranderlijk te zijn als een kameleon, met afkeer van een zogenaamd authentiek zelf. De dood van de mens mag velen onheilspellend in de oren klinken of tegen de borst stuiten, voor Foucault is het een gewaagd en opwindend experiment. Zijn inspanningen om zichzelf vorm te geven hebben in die tijd een sterk intellectueel avant-gardistisch karakter. Hij is nauwelijks politiek betrokken. Filosofie en literatuur over de ontmanteling van het zelf vormen het voornaamste referentiekader.

In de boeken uit de genealogische periode ontwikkelt Foucault zijn theorie over de disciplinerende macht. Nu beschrijft hij de decentrering van het subject als een conditionering van de mens door fysieke en bestuurlijke vormen van macht. Of er nog wel ruimte is om aan de dwang van het systeem te ontkomen, blijft daarbij angstig onduidelijk. Zelf trekt Foucault nooit de conclusie dat verzet geen zin heeft. Hij stort zich juist op het actievoeren, waarin hij een mogelijkheid vindt om de ontmanteling of overschrijding van het zelf concreter te maken. Ontegenzeglijk liep het linkse activisme van die tijd soms uit op het gebruik van geweld (bijvoorbeeld de RAF in Duitsland). Vanuit een politiek gezichtspunt trekt het ontsporende geweld de meeste aandacht. Een tweede lijn wordt daardoor wat aan het oog onttrokken. Foucaults inwisseling van de taal voor de macht voert namelijk niet alleen in de richting van strijd en geweld, maar ook in de richting van een onderzoek naar de materiële, technische conditionering van de bestaanswijze van de mens.

Vanaf ongeveer 1976 verandert Foucault nogmaals van richting. Als Foucault in de genealogische periode al hoop bood, dan leek deze te liggen in de bevrijding van de macht, of in ieder geval in het volhouden van het verzet. In zijn late werk radicaliseert Foucault de gedachte van de geconditioneerdheid van het menselijk bestaan. Hij beschouwt iedere vorm van mens-zijn als het resultaat van disciplinering. Die ontdekking gebruikt hij nu niet meer alleen om bestaande opvattingen over het subject te ontmantelen. Als aanvulling onderzoekt hij vanuit het perspectief van individuen hoe zij omgaan met de omstandigheden en regels waarmee ze geconfronteerd worden. Als nooit tevoren poogt Foucault op positieve wijze zijn eigen visie op het menselijke handelen, vrijheid en ethiek te ontwikkelen. Rond het centrale thema van de 'zorg voor zichzelf' bepleit Foucault een ethiek als levenskunst. Tijdens een interview in 1983 drukt hij dit idee misschien wel het krachtigst uit: 'Maar waarom zou niet ieders leven een kunstwerk 
kunnen zijn? Waarom is een lamp of een huis wel een kunstwerk en ons leven niet?' (DE, II, 1211). In een tijd waarin Foucault geniet van de toegenomen mogelijkheden voor een eigen levensstijl als homoseksueel, gaat hij zijn eigen werk openlijker beschrijven als een reflectie op persoonlijke problemen en de maatschappelijke context van zijn tijd.

De theoretische verschuiving van het weten via de macht naar het subject weerspiegelt zich dus in de presentatie die Foucault geeft van zichzelf als auteur. Aanvankelijk ontkent hij de betekenis van een auteur. Later spreekt hij openlijk over hoe zijn eigen bestaan de inzet van zijn filosofie is. Het is mijn overtuiging dat, juist omdat Foucault direct en concreet zijn eigen bestaan op het spel zet, zijn latere werk alleen nog maar radicaler is dan het daarvoor al was.

\section{Een overzicht van Foucaults late werk}

Foucaults laatste periode leek aanvankelijk te bestaan uit de boeken die vlak voor zijn dood in 1984 verschenen: Het gebruik van de lust en De zorg voor zichzelf. Sinds die tijd zijn echter steeds meer teksten beschikbaar gekomen: de verzamelde lezingen en interviews, en de lessen aan het Collège de France waarvan de publicatie nog gaande is. De nieuwe publicaties geven een breder beeld van Foucaults denken dan de boeken alleen. Naast de 'zorg voor zichzelf' uit Foucaults laatste boeken wil ik hier ook de thema's van de 'kritische houding', 'spiritualiteit' en 'parrèsia' uitlichten. Deze thema's worden verbonden door de kernvraag in Foucaults late werk: op welke wijze betekent filosoferen het op het spel te zetten van het eigen bestaan?

Zorg voor zichzelf. Foucaults laatste boeken handelen over de geschiedenis van de seksualiteit. Daarmee vervlochten is echter een studie naar de zorg voor zichzelf die ook los van het thema van de seksualiteit relevantie heeft. Een systematische uitleg ervan is te vinden in de 'Inleiding' in Het Gebruik van de Lust (GL, 7-34), die een kerntekst is voor de bestudering van de late Foucault. Op zoek naar het ontstaan van de disciplinaire macht dook Foucault steeds verder terug in de geschiedenis. Hij raakte gefascineerd door Griekse en Romeinse vormen van ethiek, die niet uitgaan van universele regels en principes, maar zich laten omschrijven als 'bestaanskunsten'. Foucault ontdekt dat ondanks de afwezigheid van absolute regels de ethiek van de oudheid niet ontaardde in algehele losbandigheid. Tegenover de nadruk die de moderne tijd legt op de wet stond namelijk in de oudheid een nadruk op de praktische kunst om je eigen leven vorm te geven. Het doel van deze ethiek was niet gehoorzaamheid, maar meesterschap over je eigen leven.

De zorg voor zichzelf moet volgens Foucault altijd een aspect van de ethiek zijn. Dit vormende aspect van de ethiek is echter verwaarloosd geraakt als vaardigheid van individuen. Zelfzorg werd steeds meer uitbesteed aan instellingen, eerst de christelijke 
zielzorg, later het onderwijs en psychotherapieën. Foucault wil niet terug naar de feitelijke situatie in het oude Griekenland; hij beseft terdege dat de kunst om het eigen leven te stileren een elitaire aangelegenheid was in een samenleving waar vrouwen en slaven achtergesteld werden. Maar dat er een ethiek mogelijk is waarbinnen technieken en oefeningen om je zelf te besturen worden gezien als een individuele kunst en niet als een zaak van disciplinerende instellingen, spreekt Foucault erg aan. Het is duidelijk dat hij persoonlijk gefascineerd was door de idee van zelfcreatie en de opvatting van het leven als een kunstwerk. Maar los daarvan meent hij ook dat de postmoderne, seculiere samenleving behoefte heeft aan een vernieuwing in de ethiek. Volgens Foucault moet die worden gezocht in een heroriëntering op de bestaanskunsten (vgl. Foucault 2002).

Kritische houding. Terwijl Foucault voor zijn geschiedenis van de seksualiteit steeds verder terug gaat in de tijd, verandert ook zijn kijk op de moderne tijd. Daarbij wordt het strakke kader van de disciplinerende macht langzamerhand losgelaten voor een onderzoek naar wat Foucault rond 1978 gaat omschrijven als 'gouvernementaliteit', of ook wel de 'kunst van het besturen'. Met deze begrippen wijst hij op de toename van methoden voor bestuur in de moderne samenleving. In Discipline, toezicht en straf stelde Foucault nog dat de 'mens van het humanisme' het effect is van de disciplinerende macht, zoals een soldaat in het leger wordt gekneed uit vormloze klei (DS, 188). Nu stelt Foucault echter dat mensen, zodra zij aan bestuur worden onderworpen, ook een kritische houding ontwikkelen en zich afvragen: 'Hoe niet op die manier, in naam van die principes, met het oog op die doeleinden en door middel van die procedures te worden bestuurd?' (Foucault 1994, 67) Zowel qua thema als toon neemt Foucault afstand van zijn eerdere analyse waarin het subject enkel een slachtoffer van de macht leek te zijn.

Deze ontwikkeling loopt door tot wat als tweede kerntekst uit Foucaults late werk kan gelden: het artikel 'Wat is Verlichting?'. Deze tekst verscheen in1984, nadat Foucault al overleden was. Het is een commentaar op Kant. Maar Foucault vergroot één aspect van Kants denken enorm uit, waardoor hij Kant als voorloper van zijn eigen manier van filosoferen kan presenteren. Door zich te buigen over de Verlichting zette Kant de filosofie in voor de analyse van de actualiteit. Volgens Foucault was dit een nieuw soort vraagstelling. Wat Foucault fascineert, is de onvermijdelijke dubbelzinnigheid van het antwoord op dit type vragen over de actualiteit. Enerzijds was de Verlichting een historisch proces dat zich objectief aftekende. Maar tegelijkertijd was en is het een project dat alleen bestaat als mensen zich ervoor willen blijven inzetten (Foucault 2000, 71). De waarheid over de Verlichting hangt af van de gezamenlijke inspanning van de mensen. Ook bij dit thema benadrukt Foucault dus dat kennis niet los kan worden gezien van degene die kennis ontwikkelt.

Foucault wil de Verlichting niet zien als een periode of een doctrine maar als een filosofische houding die blijvende inzet vraagt en waarvan de kritiek voortdurend 
vernieuwd moet worden. Voor Kant betekende Verlichting zelfstandig te denken en daarmee een uitweg uit onmondigheid. Voor Foucault is het hedendaagse vervolg op dit probleem van het gebruik van de rede, hoe voorkomen kan worden dat vooruitgang in de wetenschap steeds tot intensievere vormen van disciplinering zal leiden. Daarvoor is het nodig te onderzoeken hoe de condities van ons bestaan tot stand zijn gekomen. Volgens Foucault laat dit namelijk telkens zien dat het ook anders had kunnen zijn en dit levert een startpunt voor onderzoeken en praktische experimenten om ons bestaan te veranderen.

Spiritualiteit. Onder andere James Bernauer (2004) heeft gewezen op een religieuze lijn die door heel Foucaults denken loopt. Het gaat niet zozeer om het belijden van een geloof in god maar om een verwantschap met de 'negatieve theologie', die juist het ontbreken of verborgen zijn van een god als uitgangspunt neemt. Foucaults vroege werk, hierboven beschreven als een avant-gardistische, intellectualistische poging om zichzelf als subject te ontmantelen, heeft een religieuze ondertoon omdat het zich richt tegen de zelfoverschatting van de moderne, humanistische filosofie. Foucault maakt deze verwantschap expliciet in teksten uit de jaren '60 over de religieuze thematiek bij Bataille en Blanchot. In verband met de Islamitische Revolutie in Iran probeert Foucault bovendien de term 'politieke spiritualiteit' uit (DE, II, 694). Hij probeert daarmee het 'enthousiasme' aan te duiden dat nodig is voor een revolutie: een met velen gedeeld geloof in de werkelijkheid van de revolutie, gepaard aan inzet ervoor.

Foucault herneemt het thema van 'spiritualiteit' uiteindelijk systematisch in zijn lessen aan het Collège de France uit 1982. Hij bespreekt dan voor-moderne opvattingen die benadrukten dat wie kennis wil verwerven altijd moet worden ingewijd, of eerst zichzelf moet voorbereiden of veranderen. Foucault gebruikt de term spiritualiteit om aan te duiden dat kennisverwerving het subject niet onberoerd laat. Spiritualiteit in deze zin verhoudt zich slecht met wat in de moderne tijd onder objectief en wetenschappelijk wordt verstaan, maar viel volgens Foucault in de oudheid samen met de beoefening van filosofie (Foucault 2001, 16-20).

Parrèsia. Een laatste onderwerp in het late werk van Foucault is de praktijk die in de oudheid parrèsia werd genoemd, oftewel 'vrijmoedig spreken'. Het verbaast niet dat Foucault bewondering had voor een opvatting van filosofie die het als een deugd zag om tegen de gevestigde orde in te denken. In het allerlaatste college, drie maanden voor zijn dood, bespreekt Foucault Diogenes de Cynicus (zojuist verschenen: Foucault 2009). Bij Diogenes ging parrèsia verder dan de vrijmoedigheid om de waarheid zeggen tegen de gevestigde orde in. Hij was berucht om zijn scandaleuze manier van leven en had als levensinstelling om opzettelijk de waarheid te provoceren. Hij deed dit in de dubbele betekenis van provocatie: enerzijds het uitdagen van de waarheid, anderzijds een nieuwe waarheid voortbrengen door het voorbeeld van zijn leven. Zoeken naar de waarheid over 
het menselijk bestaan nam bij Diogenes de vorm aan van het zoeken naar de grens van wat nog geleefd kan worden. In Foucault laatste college verkende hij zo de uiterste mogelijkheid van het filosoferen met het eigen bestaan als inzet.

Tot slot van dit overzicht van thema's in Foucaults late werk, wil ik opmerken dat filosofie met het eigen leven als inzet niet de radicale vorm als bij Diogenes hoeft aan te nemen. De algemene les die Foucault heeft proberen over te brengen is hoe onder het mom van objectieve wetenschap het subjectieve menselijk bestaan op het spel wordt gezet en wordt omgevormd. Tegenover het 'wetenschappelijk doorgronden' van wat de mens ten diepste is, bepleit Foucault daarom hernieuwde aandacht voor de 'zorg' voor het menselijke bestaan en de 'zelftechnieken' waarmee mensen hun bestaan vormen en omvormen.

De actualiteit van Foucault: maatschappelijke problemen rond technologie

Hoewel Foucault nauwelijks expliciet over techniek heeft geschreven, bevat zijn werk veel aanzetten om de maatschappelijke invloed van techniek te analyseren. De meest voor de hand liggende aanknopingspunten zijn te vinden bij de fysieke conditionering van mensen als onderdeel van de disciplinerende macht. Deze materiële lijn in Foucaults is vaker opgemerkt. Maar navolgers hebben ook steeds gevoeld dat er een grote uitdaging lag in het formuleren van alternatieven en het vinden van een uitweg uit de allesdoordringende macht (zie Feenberg 1991; Zwart 1995; Achterhuis 1998). Een dergelijke uitweg is te vinden in Foucaults eigen latere werk. Het is dan nodig om de materiële conditionering van het bestaan die Foucault bespreekt in verband met de discipline ook te verbinden met de zorg voor zichzelf. Foucault zelf heeft dat nauwelijks gedaan. In het vervolg maak ik duidelijk hoe dit kan, aan de hand van een actueel voorbeeld: de OV-chipkaart. Het is tevens mijn bedoeling om hiermee te laten zien dat een techniekkritiek vanuit de late Foucault een originele analyse oplevert van de actuele controverse rondom deze technologie.

Dit jaar zou in heel Nederland de OV-chipkaart worden ingevoerd. Dit is een betaalkaart voor al het openbaar vervoer die werkt door middel van een RFID-chip (Radio Frequency Identification). Deze kan op afstand 'gelezen' worden zodat men de kaart, net als bij een elektronische toegangspas, alleen maar in de buurt van een lezer hoeft te houden. De invoering heeft echter vertraging opgelopen. Naast de technische en organisatorische moeilijkheden die overwonnen moeten worden, heerst er een groot maatschappelijk wantrouwen. Het College voor Bescherming van Persoonsgegevens (CBP 2007) heeft in Amsterdam de toepassing van de OV-Chipkaart onderzocht. Het oordeel was dat er te veel gegevens over personen en hun reispatronen worden verzameld, en dat er onvoldoende bescherming is tegen ongewenst gebruik van de data voor bijvoorbeeld 
persoonsgerichte reclame. Daarnaast ontstond een heuse rel, die niemand in Nederland zal zijn ontgaan, toen bekend werd dat de OV-chipkaart was 'gekraakt'. Experts van de universiteit in Nijmegen slaagden erin de beveiligingstechniek van de kaart te ontrafelen, zodat zij een kaart konden lezen en klonen (Van den Broek 2008).

De kritiek op de OV-chipkaart, zowel wat betreft de bescherming van persoonsgegevens als het technische beveiligingslek, richt zich op de mogelijke aantasting van privacy. Foucaults werk biedt krachtige instrumenten om een dergelijk vraagstuk aan te pakken. Voor een evenwichtige analyse is het late werk over subjectivering daarbij onmisbaar. Voor ik daaraan toekom zal ik echter eerst de opbrengst en beperkingen laten zien van een analyse in termen van disciplinerende macht en biopolitiek. Deze benadering van Foucault is aantrekkelijk omdat het een uiterst kritische instrument is. Door de OVchipkaart te vergelijken met het Panopticon kan worden onderzocht hoe mensen door deze technologie worden gedisciplineerd tot gedweeë volgers van het systeem. Foucault liet immers zien dat de architectuur van het Panopticon een machtseffect heeft. Dat een enkele toezichthouder vele gevangenen tegelijk onder controle kan houden, lukt niet doordat hij daartoe juridisch gezien gemachtigd is, en ook niet doordat hij fysiek zoveel sterker is, maar door het technisch ontwerp van het Panopticon. De vraag die hieruit volgt, is in hoeverre de OV-chipkaart een bijdrage is aan de door Foucault voorspelde verspreiding van het 'panoptisme' over de gehele samenleving.

De OV-chipkaart heeft inderdaad duidelijk een disciplinerend effect. Uiteraard met als doel om zwartrijden tegen te gaan, is het nieuwe systeem erop gericht iedereen beter dan voorheen in het gareel te krijgen. De verplichting tot in- en uitchecken wordt daarbij strikt afgedwongen door de techniek van RFID-kaart en poortjes op de stations. Naast deze op individuen gerichte disciplinering is er ook een 'biopolitiek' effect. Het systeem verzamelt data over reisbewegingen. Die kunnen en zullen worden gebruikt om de dienstregeling te optimaliseren. Maar de techniek biedt meer mogelijkheden, zoals prijsverhogingen in de spits, of persoonsgerichte reclame voor abonnementen. Er is kortom een scala van mogelijkheden voor het gebruik van reisgegevens. Aan de ene kant is er de onschuldige optimalisatie van de diensregeling. Aan de andere kant ontstaan er mogelijkheden voor een uitgekiende beïnvloeding van stromen reizigers. Dit soort mensenmanagement, waarbij de verzameling van gegevens middels statistische bewerkingen wordt ingezet voor beleid op het gedrag van reizigers, is precies wat Foucault aanduidt met de term 'biopolitiek'.

Hoewel ik de privacy-bezwaren tegen de OV-chipkaart niet wil of kan ontkennen, acht ik de uitgeoefende kritiek onbevredigend. Analyses als deze, die het probleem van de techniek voorstellen als een strijd tussen de menselijke vrijheid tegen een oprukkend technisch systeem, zijn heel bekend uit techniek- en maatschappijanalyses uit de tweede helft van de twintigste eeuw. Men kan denken aan het werk van Heidegger, Ellul of 
Marcuse, of ook aan Orwells roman 1984, waarin Big Brother een rol speelt die wel vergelijkbaar is met het Panopticon bij Foucault. De verdienste van deze analyses is de ontdekking dat subjectiviteit mede door de invloed van techniek vorm krijgt.

Problematisch is echter dat in deze beïnvloeding alleen een gevaarlijke vervreemding van een oorspronkelijke vorm van subjectiviteit wordt gezien, die zogenaamd vrij is van de invloed van techniek. De grote verdienste van Foucaults late werk is dat hij als vervolg op zijn al te eenzijdige machtsanalyse naar begrippen heeft gezocht om de omvorming van subjectiviteit te kunnen begrijpen. Door ook die analyse te verbinden met de sturende invloed van technologie ontstaat een nieuwe benadering. In plaats van terug te deinzen voor de ontdekking van de invloed van techniek, wordt het mogelijk om die invloed beter bloot te leggen en er het onderwerp van de zorg voor ons bestaan van te maken.

Daarom wil ik nu onder de aandacht brengen hoe mensen door het alledaagse gebruik van techniek hun eigen subjectiviteit omvormen. Het is namelijk opvallend dat de OV-chipkaart bijzonder veel aandacht heeft getrokken, terwijl er vele andere nieuwe technologieën zijn met vergelijkbare effecten, waarbij het probleem van privacy en vrijheid niet op dezelfde wijze wordt ervaren en bekritiseerd. Via mobiele telefonie, bijvoorbeeld, zijn de meesten van ons sinds een jaar of tien al permanent te lokaliseren. In dit geval is dat een bijeffect waarvan mensen zich meestal niet bewust zijn, behalve bijvoorbeeld toen onlangs bleek dat een 'sms-bom' van de politie over een schietpartij veel kinderen aan het schrikken had gemaakt (Jeugdjournaal, 21-1-2009). Bij navigatiesystemen lokaliseren mensen zichzelf moedwillig via GPS, om zichzelf als het ware vanuit de ruimte te zien en zo over het aardoppervlak te kunnen navigeren. Twitter is de laatste internethype: een website waarop mensen zichzelf welbewust zichtbaar maken voor de rest van de wereld, door van minuut tot minuut te melden waar ze zijn en wat ze doen.

Door het gebruik van deze technologieën en het invoegen ervan in hun leven zetten mensen op een actieve wijze oude opvattingen over privacy overboord en vormen ze nieuwe levenswijzen waarin privacy een andere vorm krijgt. Het in gebruik nemen van nieuwe technologieën is onvermijdelijk een proces waarin mensen hun subjectiviteit omvormen. Het is daarbij te eenvoudig om te zeggen dat mensen worden onderworpen aan de discipline van nieuwe technologieën. In veel gevallen zijn mensen gefascineerd door de nieuwe technische mogelijkheden en spelen zij een actieve rol bij het zich schikken naar de discipline van de technologie. Zich 'schikken' moet niet begrepen worden als passieve onderwerping aan techniek, maar als een actieve toe-eigening waarin de eigen subjectiviteit opnieuw gestalte krijgt in interactie met technologie. Evengoed als het waar is dat de invloed van techniek vaak oude ervaringen van vrijheid en privacy schendt, is ze de materiële conditie van een nieuwe ervaring van vrijheid. 
Dit werd mijzelf nog eens duidelijk, toen ik onlangs met de trein van Amsterdam naar Enschede reisde en onderweg besloot om een bezoek aan mijn zus in Zutphen in te lassen. Ik moest een omweg maken, terwijl ik al een kaartje had voor de rechtstreekse reis. Een extra kaartje was nodig, terwijl ik ook al betaald had voor een traject dat ik niet meer aflegde. Het gebrek aan flexibiliteit van het papieren kaartje frustreerde mij erg. Het werd mij duidelijk dat het systeem van het treinkaartje uit de tijd aan het raken is. Dat komt niet alleen doordat nieuwe technologie effectiever is, maar nadrukkelijk ook doordat het disciplinaire regime van het papieren kaartje niet meer aansluit bij de mens van vandaag. Gewend aan de continue beschikbaarheid van alle mogelijke informatie, plannen we de snelste route via een navigatiesysteem, het beste tijdstip om te vertrekken met de buienradar (buienradar.nl of meteox.be), enzovoort. Hoe wij ons gedragen, een plan trekken en daarin onze zelfstandigheid ervaren, steunt in grote mate op nieuwe netwerktechnologieën.

Naast het gebrek aan flexibiliteit, past ook de controle en het knippen van het kaartje door een conducteur nauwelijks meer bij onze huidige opvatting van zelfstandigheid. De OV-chipkaart is deel van een disciplinair regime, maar het treinkaartje is dat net zo goed. In dat specifieke disciplinaire systeem is het knippen van het kaartje een gebaar van goedkeuring voor het keurig volgen van de procedure van het vooraf plannen van een reis en het kopen van het vereiste kaartje. Mensen van vandaag en morgen hebben dit type toezicht en bevestiging niet nodig om zichzelf een deugdzaam persoon te achten. Veeleer zal deze controle als bemoeizuchtig en betuttelend worden opgevat. Bij een op flexibiliteit en continue toegang tot informatie steunende subjectiviteit past het veel beter om per gereisde kilometer direct en automatisch af te rekenen. Ook hier geeft het perspectief van de zelftechnieken, namelijk hoe mensen zelf hun subjectiviteit vormgeven in een specifieke technische context, een inzicht dat het schema van privacy tegenover technisch systeem overstijgt.

Mijn conclusie is dat een kritiek op de OV-chipkaart die uit is op absolute veiligheid en waarborging van privacy weinig adequaat is. Wij zijn alle dagen bezig onze subjectiviteit, inclusief de rol van privacy daarin, om te vormen via het gebruik van technologie. Foucaults machtsanalyse bracht ons op het spoor van de sturende effecten van techniek, ook van de OV-chipkaart. Met die analyse kan er echter geen recht aan worden gedaan dat de flexibiliteit van de OV-chipkaart tegemoet komt aan een nieuwe vorm van vrijheid en zelfstandigheid die we onszelf als eis stellen. De vraag is niet zozeer of nieuwe technologieën onze vrijheid garanderen, maar of er te leven valt met de specifieke vormen van sturende en ondersteunende invloed van techniek. Om ook dat in het onderzoek te betrekken biedt Foucaults latere perspectief van de zelftechnieken een onmisbare aanvulling. 
Bernauer, J. (2004), 'Michel Foucault's philosophy of relegion: An introduction to the nonfascist life'. In: James Bernauer en Jeremy Carette (red.), Michel Foucault and theology: The politics of religious experience. Aldershot en Burlington: Ashgate, 77-97. Broek, P. van den (2008), 'De schokgolf na de ontmanteling'. Vox 8/15: 14-18.

CBP (2007), OV-chipkaart: Verwerking van persoonsgegevens ten behoeve van de OVchipkaart bij het GVB te Amsterdam. Den Haag: College Bescherming Persoonsgegevens.

Elders, F. (1972), Michel Foucault. (Internationaal Filosofen Projekt, 1971-1973). Utrecht: RU Bureau Vormingswerk / Leusden: ISVW.

Foucault, M. (1994), Kritiek en Verlichting. Krisis. Tijdschrift voor filosofie. 14/2: 64-79.

Foucault, M. (2001), L'herméneutique du sujet: Cours au Collège de France (1981-1982). Parijs: Seuil en Gallimard.

Foucault, M. (2002), Waarom zou niet iedereen van zijn leven een kunstwerk kunnen maken? In: Dohmen, Joep (red.), Over levenskunst. De grote filosofen over het goede leven. Amsterdam: Ambo, 309-323.

Foucault, M. (2004), De ethiek van de zorg voor zichzelf als vrijheidpraktijk. In idem, Breekbare vrijheid: teksten en interviews. Amsterdam: Boom en Parrèsia, 181-207. Foucault, M. (2009), Le courage de la vérité: Cours au Collège de France (1983-1984). Parijs: Seuil en Gallimard.

Jeugdjournaal, 21-1-2009. 'Sms over schietpartij'.

(http://www.nos.nl/jeugdjournaal/artikelen/2009/1/21/smsoverschietpartij.html) 